\title{
Research on the College Entrance Examination Enrollment Reform Based on Equity Theory Under the New Situation
}

\author{
Yang Xueying $^{1 *}$, Long Yuhang ${ }^{2}$ \\ ${ }^{1}$ School of economics and management, Changchun University of Technology, Changchun, Jilin 130012, China \\ ${ }^{2}$ Admissions Office, Changchun University of Technology, Changchun, Jilin 130012, China \\ *Corresponding author. Email:xueying_y@126.com
}

\begin{abstract}
This article is mainly combined with the development and changes of China's college entrance examination admission system over the years, to explore the problems of the fairness of the admission system, and actively explore ways to solve problems and countermeasures. In view of the current situation in China and some foreign countries, we will analyze the advantages and disadvantages of various models of higher education examinations and adapt them to the national situation; we will conduct a comparative analysis of various models from the perspective of fairness, and on this basis, we will make recommendations for the improvement of the model of higher education examinations in China, Finally we will propose ideas for the problems that have not yet been solved.
\end{abstract}

Keywords: fairness theory, reform of the higher examination model, higher examination admission

system

\section{INTRODUCTION}

The reform of college entrance examination mode has always been a hot topic in the educational field. In 2019, the number of college entrance examination applicants in China exceeded 10 million, and the enrollment rate was $90 \%$, which has entered the stage of popular education. How to ensure the scientific, fair and economical nature of the higher education examination model in such a largescale, nationwide unified examination is a major issue that concerns the country and people's livelihood.

At present, the key issues about the reform of college entrance examination mode are mainly focused on the subjects, methods, modes and plans of college entrance examination. It involves many theoretical and technical problems, such as whether the college entrance examination is fair, the proposition and mode are reasonable, or the distribution of the enrollment plan is rational. The relevant research institutions mainly consist of the student Department of the Ministry of education and the recruitment and examination institutions. They focus on the way of college entrance examination, such as times, subjects and contents. This article attempts to explore the reform of the college entrance examination model from the perspective of admission system reform.

\section{DEFINITION OF CORE CONCEPTS}

\subsection{Equity theory}

Equity theory is an incentive theory proposed by American behavioral scientist Stacey Adams. The basic thrust of the theory is that human motivation to work is not only related to how much an individual is actually paid, but also more closely to whether people feel that the distribution of compensation is fair. People will always, consciously or unconsciously, compare the price they pay for their labour and the remuneration they receive with others, and make judgements about fairness or otherwise. China's current model of the university entrance examinations has problems such as the obvious differences in the admission ratios of candidates from different places of residence and the deviations in the implementation of the policy of adding points to the university entrance examinations in some areas, which have seriously affected the authority and fairness of China's university entrance examinations system. The term "equity" in this study refers to three main aspects: equity in admissions, equity in information and equality of opportunity. 


\subsection{Recovery and pilot phase: 1977-1984}

\subsection{Higher education examination system}

The so-called formal higher education examination system refers to the written rules (including rules, regulations, rules and guidance) that are formulated and implemented by the government, education or examination authorities and that have a compulsory effect on people's behaviour in higher education examinations. According to the compo sition of the college entrance examination system, it mainly includes the college entrance examination test system, college entrance examination admission system and college entrance examination management system three subsystems.

\subsection{Admission to the Higher Education Examination System.}

Admission is the result of a series of college entrance examination activities, that is, according to a certain number of enrollment, the examination results or comprehensive evaluation, talents are selected from the best. In a certain sense, the examination and management activities of college entrance examination are carried out around the purpose of admission. Admission system is about the selection between colleges and examines. It mainly includes a series of rules, such as admission system, enrollment quota, admission method, admission method and admission technology.

\section{HISTORICAL DEVELOPMENT OF THE REFORM OF THE ENTRANCE EXAMINATION SYSTEM MODEL}

\subsection{Exploration phase: 1949-1965}

Beginning in 1952, our country formally established a national unified examination system for higher education. The admission system of this period was known as the Unified Allocation System, whereby central admissions commissioners made uniform admissions and allocated them to universities. However, admissions are smaller, more subjective and lack experience with large-scale examinations.

\subsection{Stagnation stage: $1966-1976$}

It was a special period in our politics. the admission system of the college entrance examinations during this period had strong political overtones, with a very small percentage of admissions.
In 1978, the National Unified Examination System was formally restored. Pre-selection examinations are conducted, and outstanding talents are selected by the municipal autonomous regions in conjunction with their high school performance; the system of entrance examinations is based on the entrance examinations for higher education, and recruitment is conducted on the basis of the entrance examinations.

\subsection{Diversified reform stage: 1985-1999}

One is the scientific standard of the higher education examination system. The second is the diversification of the content of the examination. During this period, the content of the examination was constantly experimented with, and the design of the questions changed considerably, the content of the examination became more extensive, Focusing on quality education for candidates, the " $3+2$ programme" is divided into two categories: arts and sciences.

\subsection{In-depth reform stage: from 1999 to now}

Higher education has entered the stage of large-scale expansion of recruitment, and the Ministry of Education has issued the Opinions on Further Deepening the Reform of the General Higher Education Admission Examination System, thus unveiling the stage of deepening the reform of the higher education examination system.

\section{PROBLEMS WITH THE FAIRNESS OF CHINA'S ENTRANCE EXAMINA - TION SYSTEM IN}

Because of the vast territory of our country, The game between "college entrance examination fairness" and "regional fairness" has never stopped.

\subsection{The content of the entrance examination is different}

Since 1989, China has taken the lead in implementing independent proposition in Shanghai. In 2016, except for Beijing, Shanghai, Tianjin, Jiangsu and Zhejiang, other provinces chose the national unified test paper.

On the one hand, authority is questioned. The independent proposition of college entrance examination enrollment mainly refers to the proposition made by the teachers of the province formulated by the ministry of education. This provides more convenience. The different propositions caused the different difficulty degree of the college entrance examination paper in different provinces, and the scores of the college entrance examination could not be 
China. Among them, Beijing has 8985 universities, ranking first, Shanghai has 4 . The uneven distribution of education resources leads to uneven distribution.

On the other hand, the necessity of autonomous propo sition in developed areas is questioned. In the proposition of returning to unity after 2016, the remaining five autonomous provinces are all economically developed regions. However, these regions are superior to other provinces in terms of educational resources and educat ional level. The independent proposition of five provinces will make the masses doubt the role brought by the balance of power, which has an adverse impact on social fairness.

\subsection{The difference of score line in college entrance examination}

For many years, our country has been implementing the policy of taking Province as the unit to determine the number of admission places and delimit the admission score line of college entrance examination. We take the entrance examination score line of some provinces in 2017 as an example. In 2017, there are only five provinces with independent proposition, Beijing, Shanghai, Tianjin, Jiangsu and Zhejiang. In areas with relatively backward economy and culture, the minimum admission control line is also relatively low; in areas with relatively developed economy, there will be partial inclination in policy. In 2017, Jiangxi's admission control line was about $10 \%$ higher than Guangdong's, while Chongqing's was more than 50 points higher than Inner Mongolia's. Although this measure offered preferential policies to remote areas, it also resulted in the phenomenon of college entrance examination immigrants. In the same examination paper, developed areas still have certain advantages, which undoubtedly protect the examinees in these areas.

\subsection{The difference of enrollment rate in college entrance examination}

\subsubsection{Localization tendency of universities.}

Part of the universities in China enjoy the central financial expenditure, and part of them rely on local financial support. Therefore, local financial support schools will be more closely connected with the government, and will benefit the local government by increasing the number of local students to obtain more financial support.

\subsubsection{The distribution of university resources is unbalanced.}

University resources are still relatively scarce in China, especially in universities like "985 Project" and "211 Project". Up to now, there are 39 universities entering "985 Project" in China, which are distributed in 18 cities in

\subsubsection{Fairness of independent enrollment.}

The independent enrollment system has brought a great deal of subjective color and caused people's great concern. But this policy has greatly increased the independent choice right and the distribution right of colleges and universities. However, there are also certain moral risks. The inequality of some rights and resources leads to the impact on the fairness of the right of choice.

\section{FOREIGN COLLEGE ENTRANCE EXAMINATION MODEL BASED ON FAIR}

The college entrance examination in the United States has strict evaluation criteria. The SAT is evaluated on two tests, the scholastic aptitude test and the American college entrance exam. The SAT emphasizes the ability to use knowledge and also measures academic ability. Compulsory exam course is English, read, maths, science reasoning 4 , which hold 5 times a year exam. What also plays a greater role is the extracurricular students' practice and recommendation letters. Since many of America's best universities are private, much power rests with state governments. Considering its own development and social influence, the school will recruit students for political, cultural, religious, ethnic and other reasons.

\section{MEASURES TO IMPROVE THE FAIR SYSTEM}

\subsection{Diversified reform based on Unification}

First of all, the higher education examination system should be based on a unified examination. After decades of continuous exploration and improvement, the unified examination format has ensured the basic equity of society's educational resources and diversified development.

Second, merit-based selection on the basis of a uniform examination. Borrowing from the U.S. college entrance examination system which has some significance in the selection of outstanding candidates with diversification of examination subjects. In the selection of subjects in the higher education examination, the subject settings should be refined; colleges and universities should develop admission plans through the different needs of different majors one by one, so as to facilitate more effective admission of the required talents. In our country's college entrance examination system, the selection is mainly divided into two grades, one and two, the government can through the college entrance examination does not identify specific colleges and universities, only the way to divide 
the grade is a good first hurdle, then through the school's own demand feedback to the education department, the second examination in a nationwide unified way, that is, to avoid the one examination to determine life, but also to improve the demand for college admission.

\subsection{Increase education support in remote areas}

First we should unify the content and adhere to the inclination of the score line of college entrance examination. The policy inclination to the western region has always been a system. However, the difference of test content can not accurately quantify the extent of tilt, which puts forward the difficulty for the accuracy of the policy. Unifying the content of the test and putting the tilt strength on the score can improve the clarity of the policy.

Secondly, we should develop local examinees to help the local economy. For the candidates from remote areas who pass the lower college entrance examination scores and enter the colleges and universities in developed areas, the state provides financial support. At the same time, they are required to return to the examination place for employment after finishing their studies.

\subsection{Improve the fairness reform of Independent Enrollment}

We will increase the number of independent students in the western region. Due to the uneven distribution of resources and the backwardness of education in the west, the central and western regions have a weak position in the process of independent enrollment. Increasing the number of candidates in the underdeveloped areas is the fundamental guarantee for the independent enrollment in the western areas; secondly, more preferential measures should be set up to reduce the educational disadvantage of candidates in the western areas due to the uneven distribution of resources.

We will improve the supervision system for independent enrollment in Colleges and universities. We should strengthen the supervision and control of the loopholes in the high autonomous enrollment. We will publicize and supervise each link and standard of independent enrollment, so that citizens can better understand the whole process of independent enrollment, and realize the decentralization of rights and mutual supervision. Finally, the government set up a set of supervision system to cooperate with the independent recruitment system.

\subsection{Adjust the layout of college entrance examination Resources}

Adjusting regional exchanges, we will improve cultural and educational exchanges among regions. The imbalance of educational resources is the main reason for the imbalance of education. First, the state should support education in remote areas in terms of policies, funds and teachers. Send talents with high academic ability and rich experience to remote areas for guidance, exchange and study. Secondly, we should combine the situation of the western region, develop more specialties in line with the advantages of the western region, and highlight the advantages of running schools in the western region. Finally, we should combine some schools with poor conditions, integrate resources and establish a competitive school.

By adjusting the layout of colleges and universities, the central deployment of colleges and universities should play a leading role in inclining the proportion of enrollment to underdeveloped areas. The situation that the number of college entrance examination enrollment in China always inclines to Beijing, Tianjin, Shanghai and Zhejiang should be changed, and some of the indicators should be allocated to the western region. Simultaneously, it is necessary to increase the index of enrollment outside the province of provincial colleges and universities, and allocate these indexes to remote areas, which is also helpful to the development of colleges and universities themselves. Finally, the standard of enrollment and distribution of colleges and universities in our country should establish guiding documents and regulations, and to ensure the fairness and rationality of enrollment index, we should establish transparent methods to formulate policies.

\section{CONCLUSION}

College entrance examination system is a far-reaching system that affects different interest groups. It is not a zero-sum game, nor is it a relationship of elimination, but a policy of precision that maximizes the interests of all parties and achieves the common growth of all interest groups through a balance of policies.

This work was supported by Jilin Education Science Planning (NO.zd15037), Exploration and Research on the reform of new college entrance examination mode.

\section{REFERENCES}

[1] Lu Cixian. Study on the Fairness of the Higher Education Examination System [M]. Hangzhou: Zhejiang Education Press, 2017.

[2] Yang yao yao. A comparative study of the new Chinese college entrance examination system and the American college entrance examination system [J]. Journal of Jilin Provincial Academy of Education, 2018(08).

[3] Meidong Xing. The practical strategies and practical implications of the reform of the entrance examination 
system [J]. Contemporary Educational Practice and Teaching Research, 2018(06).

[4] Cao He-han. The inspiration of the Japanese university admission system on the reform of China's high school entrance examination system [J]. Inner Mongolia Education, 2018 (14).

[5] yang yao yao. A comparative study of the new Chinese college entrance examination system and the American college entrance examination system [J]. Journal of Jilin Provincial Academy of Education, 2018(08). 